\title{
ROUPA HOSPITALAR E O CUIDADO EM SAÚDE: VISÃO DOS PROFISSIONAIS E ESTUDANTES*
}

\author{
Anapaula Massinatori Peres ${ }^{1}$, Luzmarina Aparecida Doretto Braccialli², Sueli Moreira Pirolo2, Elza de Fátima \\ Ribeiro Higa ${ }^{2}$, Márcio Mielo ${ }^{3}$
}

RESUMO: Objetivo: analisar o entendimento sobre o uso da roupa hospitalar e sua importância no cuidado. Método: estudo de caso com 19 profissionais de nível superior (médicos e enfermeiros), 23 profissionais de nível médio (técnicos e auxiliares de Enfermagem) e 11 estudantes de graduação (Enfermagem e Medicina) de um hospital de ensino do interior do Estado de São Paulo, de fevereiro a junho de 2016. Para a análise dos dados, foi utilizada a Análise de Conteúdo Temática. Resultados: da análise dos dados, emergiram duas categorias: "Roupa hospitalar como um item do cuidado" e "Oferta da roupa para o cuidado".

Considerações finais: os participantes do estudo desconhecem o significado e a importância da roupa para o cuidado. São necessárias ações educativas para a compreensão de sua finalidade.

DESCRITORES: Assistência Integral à Saúde; Educação em Saúde; Pesquisa Qualitativa; Serviço Hospitalar de Lavanderia; Serviços de Saúde.

\section{HOSPITAL LINEN AND HEALTH CARE: PERSPECTIVE OF PROFESSIONALS AND STUDENTS}

ABSTRACT: Objective: analyze the understanding of the use of hospital linen and its importance in health care. Method: case study with 19 university level professionals (physicians and nurses), 23 secondary level professionals (nursing technicians and aides) and 11 undergraduate students (nursing and medicine) from a teaching hospital in the state of São Paulo, from February to June 2016. Thematic content analysis was used for data analysis. Results: two categories emerged from data analysis: "Hospital linen as a care item" and "Provision of linen for care". Final considerations: the participants were unaware of the meaning and importance of linen within the care context. Educational activities are needed to understand its importance.

DESCRITORES: Comprehensive health care; Health education; Qualitative research; Hospital laundry service; Health service.

\section{ROPA HOSPITALARIA Y EL CUIDADO EN SALUD: VISIÓN DE LOS PROFESIONALES Y ESTUDIANTES}

RESUMEN: Objetivo: Analizar la comprensión sobre el uso de la ropa hospitalaria y su importancia en el cuidado. Método: Estudio de caso, con 19 profesionales de nivel superior (médicos y enfermeros), 23 profesionales de nivel intermedio (técnicos y auxiliares de Enfermería) y 11 estudiantes de curso de grado (Enfermería y Medicina) en hospital de enseñanza del interior del Estado de São Paulo, de febrero a junio de 2016. Datos analizados por Análisis de Contenido Temático. Resultados: Del análisis surgieron dos categorías: "Ropa hospitalaria como ítem del cuidado" y "Oferta de la ropa para el cuidado". Consideraciones finales: Los participantes del estudio desconocen el significado y la importancia de la ropa para el cuidado. Serán necesarias acciones educativas para la comprensión de su finalidad.

DESCRIPTORES: Atención Integral de Salud; Educación en Salud; Investigación Cualitativa; Servicio de Lavandería en Hospital; Servicios de Salud.

\footnotetext{
*Artigo extraído da dissertação intitulada: Roupa hospitalar e o cuidado em saúde: visão dos profissionais e estudantes. Faculdade de Medicina de Marília, 2017.

${ }^{1}$ Enfermeira. Mestranda do Programa de Mestrado Profissional em Ensino em Saúde da Faculdade de Medicina de Marília. Marília-SP-Brasil.

${ }^{2}$ Enfermeira. Doutora em Enfermagem. Docente da Faculdade de Medicina de Marília. Marília, SP, Brasil.

${ }^{3}$ Enfermeiro. Doutor em Enfermagem. Docente da Faculdade de Medicina de Marília. Marília, SP, Brasil.
} 


\section{INTRODUÇÃO}

Esta pesquisa tem como objeto a lavanderia hospitalar e sua interface com o cuidado. Pressupõese que os profissionais de saúde e os estudantes de graduação dos cursos de Medicina e Enfermagem pouco reconhecem a importância do uso da roupa hospitalar no cuidado em saúde; que a formação não traz os serviços de apoio como parceiros na produção do cuidado integral e que a educação em saúde pode sensibilizar os profissionais para melhorar o uso da roupa na sua prática.

Tais pressupostos contrapõem a integralidade do cuidado na atenção hospitalar que, entre outros aspectos, deve ser humanizada e centralizada nas ações de segurança e conforto do paciente ${ }^{(1-2)}$ ao promover ambiente terapêutico e acolhedor de acordo com suas necessidades. Essa situação é atingida quando a responsabilidade se torna compartilhada entre os diversos profissionais e serviços $^{(3)}$ articulando as práticas dos profissionais envolvidos no cuidar.

Logo, os serviços que compõem o hospital têm que interagir a fim de prestar bom atendimento, incluindo o serviço de lavanderia(4). As equipes multiprofissionais devem trabalhar visando a satisfazer as necessidades dos pacientes ${ }^{(5)}$ e a descontinuidade no processo de trabalho, de qualquer uma dessas equipes, comprometerá diretamente a qualidade da assistência prestada.

A lavanderia hospitalar se constitui em um serviço importante e contribui indiretamente para o cuidado em saúde. É responsável pelo processamento e distribuição do enxoval em perfeitas condições de higiene, conservação e quantidade ${ }^{(6)}$, sendo a roupa limpa indispensável ao funcionamento eficiente de uma instituição ${ }^{(7)}$. Todos os setores do hospital são dependentes do adequado funcionamento da lavanderia, uma vez que ela auxilia no controle das infecções hospitalares, na segurança e no conforto dos pacientes.

Entre as suas responsabilidades estão as de processar as roupas com qualidade e segurança; promover ambiente de trabalho seguro aos profissionais; utilizar técnicas adequadas para o processamento; atender às necessidades dos pacientes e humanizar o atendimento por meio da oferta da roupa higienizada e em quantidade adequada ao tipo de procedimento. $\mathrm{O}$ serviço tem como finalidade o controle de infecções, a recuperação, o conforto e a segurança do paciente ${ }^{(7)}$.

É um local insalubre onde os funcionários estão expostos a riscos físicos, químicos, biológicos, ergonômicos e acidentais que interferem na segurança do trabalho e na qualidade de vida dos trabalhadores. Por isso, existe a necessidade do controle de infecções e da prevenção de riscos à saúde dos trabalhadores tendo em vista que a roupa suja pode ser um veículo de disseminação de microrganismos no momento do seu manuseio pelos trabalhadores e quando utilizada pelos pacientes ${ }^{(8)}$.

O gerenciamento da roupa é fator primordial dentro da organização hospitalar ${ }^{(9)}$ e insere os colaboradores num processo contínuo de aprendizagem para melhor desempenho do trabalho(5). Consideram-se roupas hospitalares todo material de tecido, de uso restrito hospitalar, que deve ser higienizado na lavanderia para sua reutilização. Incluem: lençóis, fronhas, cobertores, toalhas, cortinas, roupas de pacientes, uniformes, fraldas, compressas, campos cirúrgicos, máscaras, propés, aventais, gorros e panos de limpeza ${ }^{(10)}$.

A utilização das roupas de forma adequada contribui para a conservação dos tecidos e o conforto do usuário. Cada peça tem uma finalidade e os profissionais desconhecem que a falta da roupa durante o cuidado é consequência da utilização incorreta das peças. Se ocorrer uso indevido, extravio e demais perdas, o quantitativo circulante de roupa diminui e a oferta não supre a demanda, sendo necessária a reposição contínua do enxoval(4).

Atualmente, a qualidade dos serviços de hospedagem é um dos fatores que interferem na escolha do hospital pelo paciente eletivo ${ }^{(11)}$ visando a aumentar o próprio conforto e de seus familiares ${ }^{(1)}$. Representa parte da ação de reabilitação e tem por objetivo tornar o ambiente agradável, seguro e humanizado ${ }^{(11)}$. Foi criada para a contínua busca da excelência conciliando o conforto e a segurança com os objetivos do hospital ${ }^{(10)}$. 
Essa premissa, presente nas instituições privadas de saúde, deve também estar presente no atendimento público de saúde que preconiza a integralidade do cuidado e o atendimento humanizado.

Nessa direção, deve estar voltada à formação dos profissionais da saúde buscando a integralidade do cuidado com a aproximação entre teoria e prática ${ }^{(12-14)}$. Essa perspectiva envolve o gerenciamento do cuidado e a educação permanente, tendo em vista a reorganização institucional ${ }^{(15)}$, com a integração de diversas especialidades que sustentam esse processo ${ }^{(16)}$.

Dessa forma, questiona-se: qual o entendimento dos profissionais e estudantes de graduação da área da saúde sobre a importância do uso da roupa hospitalar na prática do cuidado? Assim, o objetivo desta pesquisa foi analisar o entendimento sobre o uso da roupa hospitalar e sua importância no cuidado em saúde.

\section{○ MÉTODO}

Trata-se de uma pesquisa do tipo Estudo de Caso, com abordagem qualitativa, realizada em um hospital de ensino público do interior do Estado de São Paulo.

Os participantes do estudo foram profissionais da saúde de nível superior, de nível médio e estudantes de graduação dos cursos de Medicina e Enfermagem do hospital em estudo. Os critérios de inclusão foram profissionais e estudantes atuando no momento do estudo no cuidado direto ao paciente, no período diurno, nas unidades de internação, exames complementares, centro cirúrgico, unidade de terapia intensiva, pronto-socorro e central de materiais. Foram excluídos os profissionais ou estudantes que trabalham ou estagiam em outras unidades assistenciais do complexo hospitalar e ambulatorial, aqueles que, no momento da coleta de dados, estavam de férias ou licença médica e que não utilizam a roupa no cuidado do paciente.

A amostra incluiu 19 profissionais de nível superior (médicos e enfermeiros), 23 profissionais de nível médio (técnicos e auxiliares de Enfermagem) e 11 estudantes de graduação (Enfermagem e Medicina), totalizando 53 participantes. Essa, em síntese, foi definida por saturação de dados, na qual se manteve, pelo menos, um critério de homogeneidade fundamental em cada categoria participante ${ }^{(17)}$.

A coleta de dados ocorreu no período de fevereiro a junho de 2016 por entrevista semiestruturada constituída por dados de identificação dos participantes e questões norteadoras sobre o entendimento da roupa hospitalar e sua importância para o cuidado, os motivos que causam a falta e seu processamento. O entrevistado foi codificado pela letra E acrescida de uma sequência numérica crescente: E01, E02, E03 e, assim, sucessivamente, até o total de 53.

Os dados foram interpretados pela técnica de Análise de Conteúdo, na modalidade Temática, constituída das seguintes fases: pré-análise, exploração do material, tratamento dos resultados, inferência e interpretação ${ }^{(18)}$.

A pesquisa foi aprovada pelo Comitê de Ética sob o número de protocolo 1.351.215 e os participantes assinaram o Termo de Consentimento Livre e Esclarecido antes da coleta de dados ${ }^{(19)}$.

\section{RESULTADOS}

Dos participantes, 19 (35,85\%) eram profissionais de nível superior; 23 (43,40\%), de nível médio e $11(20,75 \%)$, estudantes de graduação, sendo $41(77,36 \%)$ do sexo feminino. Referente ao local de atuação no momento do estudo, 17 (32,08\%) participantes exerciam suas atividades nas unidades de internação; dez (18,87\%), na unidade de exames complementares; nove (16,98\%), no pronto-socorro; cinco $(9,43 \%)$, no centro cirúrgico; quatro (7,55\%), na Unidade de Terapia Intensiva (UTI) e dois (3,77\%), na central de materiais. A categoria outros, com seis (11,32\%) participantes, abrangeu estudantes de graduação que estagiavam nas especialidades de cirurgia geral, clínica médica e ortopedia. 
Da análise dos dados obtidos, emergiram duas categorias analíticas: 1- roupa como um item do cuidado, constituída pelo entendimento, finalidade e tipos de peças que compõem o enxoval e 2 - a oferta da roupa hospitalar para o cuidado, ilustrada pelo processamento e motivo de sua ausência.

Na primeira categoria, quando os participantes abordaram o entendimento sobre o uso da roupa hospitalar, assim se manifestaram:

Roupas que só devem ser utilizadas dentro do hospital [...], roupas de procedimentos e roupas de uso para o funcionário, roupa esterilizada usada em procedimento estéril e capotes usados para isolamento [...]. (E23)

[...] tudo o que a pessoa utiliza quando está internada e também para realizar procedimentos no centro cirúrgico [...], são todas as roupas que são processadas para uso no hospital [...] tudo que é tecido. (E36)

Alguns entrevistados apresentaram um entendimento equivocado sobre a roupa hospitalar, assim relatado:

[...] eu imagino a roupa bem limpinha, esterilizada, quando eu penso em roupa, eu já penso nela esterilizada. (E30)

Nada, eu sei que os profissionais usam e os pacientes também. (E43)

Quanto à finalidade da roupa hospitalar, os entrevistados descreveram situações nas quais a roupa está sendo utilizada corretamente:

Em todo o cuidado direto com o paciente na sua higiene corporal e nos procedimentos cirúrgicos. O bom uso desde a sua necessidade e utilizando ela adequadamente, cada roupa para sua finalidade [...]. (E12)

Algumas falas relataram situações nas quais a roupa hospitalar é utilizada de maneira indevida.

Rasgar roupas, jogar roupa no chão para limpar, levar paciente embora de alta com roupa hospitalar. (E02)

É ir comer no refeitório e sair na rua com a roupa, levar pra casa pra lavar. (E41)

Sobre os tipos de peças de roupa hospitalar, os entrevistados descreveram:

Kit de lençol, fronha, cobertor, os uniformes, toalha [...], compressas, pano de chão [...]. (E16)

Lençóis, fronhas, forros, camisa, bermuda, camisola, enxoval dos RNs, roupas utilizadas no centro cirúrgico e em procedimentos como intracath, campos cirúrgicos, aventais, compressas, faixas de contenção, cobertores, compressas [...]. (E35)

Porém, algumas falas descrevem tipos de peças que não são caracterizados como roupa hospitalar: Calça, blusa de manga comprida, jaleco e bota [...]. (E41)

[...] jaleco, calça jeans, sapato impermeável [...]. (E49)

Na segunda categoria, quanto ao processamento da roupa hospitalar, a maioria dos participantes respondeu que não tem conhecimento sobre esse assunto:

Eu conheço as duas etapas: quando a roupa chega na área suja, é separada e depois que vai pra área limpa. (E03)

Não conheço, mas eu imagino que tem o processo de lavagem e de esterilização. (E48)

Nas falas dos entrevistados, os motivos da ausência da roupa para o cuidado estão relacionados com a atuação do profissional ligado diretamente ao cuidado, com a dinâmica de funcionamento da lavanderia, com a falta de financiamento para a reposição do enxoval, com o extravio da roupa e com o aumento da demanda de atendimento.

[...] eu imagino que é porque está tendo mau uso [...] é usar avental quando está com frio [...], é trocar o lençol sem necessidade [...]. (E36)

[...] se a lavanderia trabalhasse 24 horas, eu acho que teria a roupa suficiente. (E01) 


\section{DISCUSSÃO}

A lavanderia desempenha papel importante no contexto hospitalar e no processo de cuidar, mas é um serviço que não fica em evidência por parte dos gestores, profissionais e pacientes. É um trabalho não assistencial, sem relação direta com o paciente e, por isso, não é reconhecido e valorizado ${ }^{(20)}$.

Na primeira categoria analítica, identificou-se que, apesar da importância da roupa limpa no cuidado prestado aos pacientes, ela não é percebida pelas pessoas que a utilizam. É um item que está presente diariamente na maioria dos procedimentos realizados pelos profissionais, mas eles desconhecem o significado da roupa para o cuidado.

Os entrevistados compreendem que a roupa é destinada aos pacientes internados, aos profissionais e que é de uso restrito ao ambiente hospitalar. Porém, não relataram que a roupa deve ser processada para ser reutilizada, ou seja, para a roupa limpa estar disponível para o uso, é necessário que a mesma seja utilizada e encaminhada corretamente para a lavanderia.

O funcionamento eficaz da lavanderia hospitalar depende de um bom planejamento e, para isso, é necessária uma equipe qualificada. Nesse contexto, o enfermeiro é profissional importante no gerenciamento desse serviço, pois dispõe de habilidades como capacidade de organização, comunicação e liderança ${ }^{(21)}$.

Os entrevistados, ao definirem a finalidade da roupa, a relacionaram com os procedimentos que realizam desde a admissão do paciente até a sua alta. Cuidados como o banho foram citados por vários entrevistados, principalmente pela equipe de Enfermagem. O banho proporciona a higiene e o conforto aos pacientes, estimula a circulação, promove o relaxamento muscular e melhora a autoimagem. Realizado no leito significa prestar um cuidado integral reconhecendo a pessoa em sua totalidade ${ }^{(22)}$.

Várias situações de uso indevido que descaracterizam a finalidade das roupas também foram citadas como rasgar peças do enxoval, rabiscá-las ou retirá-las do ambiente hospitalar ${ }^{(4)}$. Por meio desses depoimentos, observou-se que as pessoas sabem que essas atitudes vão causar prejuízos ao hospital e ao cuidado, porém, é difícil a identificação de quem utiliza indevidamente as peças e nem sempre as pessoas são responsabilizadas por essas atitudes.

Todos os profissionais da Enfermagem, principalmente o auxiliar de Enfermagem, citam peças da roupa hospitalar relacionadas ao enxoval do paciente demonstrando que a roupa está dentro do seu contexto de cuidado(15). O auxiliar de Enfermagem é a categoria profissional que representa a maior parte dos profissionais que manipula os itens da roupa no momento de realizar a higiene e promover o conforto do paciente e, também, acondiciona todas as roupas utilizadas pelos médicos no centro cirúrgico, sendo, ainda, o sujeito de transformação no processo do uso da roupa hospitalar no cuidado contribuindo, assim, com a mudança das práticas.

Se, de um lado, o posicionamento dos profissionais da Enfermagem está muito próximo das roupas e do cuidado, do outro, as falas dos médicos e estudantes de graduação indicam o visível distanciamento, ao mencionar apenas o uniforme de trabalho como roupa hospitalar, não relacionando as peças ao enxoval do paciente e demonstrando que pouco articulam a roupa ao cuidado.

O uniforme é utilizado para a identificação dos profissionais e para evitar a contaminação de suas roupas, visto que são frequentemente expostos a riscos biológicos, químicos e físicos. Esses uniformes devem ser processados na lavanderia do hospital, pois podem ser vetores para a transmissão de microrganismos que causam infecções e doenças aos trabalhadores e aos pacientes ${ }^{(23)}$. 
A administração do hospital deve conscientizar os pacientes e demais usuários a respeito da preservação das peças que fazem parte do patrimônio hospitalar ${ }^{(24)}$, por meio da educação em saúde, com o objetivo de orientá-las quanto a real necessidade da utilização dessas roupas.

O processo de educação possibilita a aproximação entre a formação e a mudança da prática. Seu papel deve ser sempre revisto a fim de que os conhecimentos que produzem possam dialogar com os saberes formais e os saberes do cotidiano. Por meio da educação permanente, pode-se promover o desenvolvimento dos profissionais e realizar a transformação das práticas ${ }^{(12)}$.

A organização do cuidado deve ser orientada pela integralidade, com a interação dos pacientes e profissionais envolvidos no processo, para a construção de respostas que contemplem as necessidades de saúde dos usuários e não somente por meio da execução de procedimentos técnicos. É estar pensando em proporcionar conforto e segurança ao paciente ${ }^{(25)}$. Nesse sentido, a roupa hospitalar é utilizada não somente nos procedimentos, mas, também, para posicionar o paciente, mudar o decúbito e aquecer o corpo.

O uso indevido da roupa hospitalar na prática do cuidado é um problema e pode-se construir, com a participação dos envolvidos, propostas para a ação educativa ${ }^{(4)}$. Também é necessário pensar na formação dos profissionais da saúde que, durante a graduação, não se aproximam desse universo e desconhecem a importância desse setor para o cuidado. O perfil de formação dos profissionais deve estar voltado para as necessidades de saúde do indivíduo.

A segunda categoria analítica apresenta que a atuação dos profissionais, que estão ligados diretamente ao cuidado, interfere na falta da roupa por meio do uso indevido; problemas na organização da lavanderia e com seus colaboradores; falta de financiamento para a reposição de enxoval; extravio no momento da alta hospitalar, em ambulâncias ou pelos usuários do hospital e no aumento da demanda de atendimento diminuindo, assim, o quantitativo circulante de roupa.

A lavanderia hospitalar busca a integração mais digna do funcionário como um colaborador visto que o seu trabalho é sujo, cansativo e repetitivo ${ }^{(24)}$. Eles têm pouca compreensão da organização hospitalar, do papel da lavanderia nesse contexto e de sua importância na recuperação do paciente. Executam tarefas imprescindíveis para o bom funcionamento do hospital, mas assumem a posição de categoria inferior gerando invisibilidade social e pouco conhecimento sobre seu trabalho. Suas atividades são vistas como degradantes, ou seja, realizam o trabalho sujo ao manipular algo considerado repulsivo e que parece não ser finalizado devido à constante entrada de roupas ${ }^{(20)}$.

O trabalho sujo pode ser fator de sofrimento, algo que retira a dignidade de uma pessoa e é indesejado no plano dos ideais. Esse tipo de trabalho está associado a ambientes e situações de risco elevado, baixa remuneração e dificuldade de crescimento na carreira profissional( ${ }^{(26)}$.

Particularmente, quando se trata da evasão de roupa hospitalar por meio dos estudantes de graduação, remete-se a uma relação de poder que a roupa traz fora desse ambiente para que eles possam ser reconhecidos socialmente e a roupa, usada como fator de exposição. $\mathrm{O}$ aumento da demanda dos pacientes internados em hospitais públicos também foi citado como fator que causa a falta da roupa. Para minimizar essa falta, é importante o gerenciamento da roupa pela lavanderia ${ }^{(9,11)}$.

Com relação ao processamento da roupa hospitalar, somente um entrevistado respondeu conhecer como a roupa é processada e suas etapas. Os profissionais de saúde e estudantes de graduação desconhecem o fluxo da lavanderia e não compreendem que todos os envolvidos com a roupa hospitalar podem contribuir diretamente para melhorias desse serviço de apoio, pois fazem parte desse processo.

As pessoas que manipulam as roupas devem ser conscientizadas quanto à sua importância para que não haja desperdício e para que elas compreendam que suas ações interferem diretamente na organização dos diversos setores do hospital, inclusive, na lavanderia.

Como limitações do estudo, houve dificuldade na busca por referências bibliográficas devido à carência de produção científica. 


\section{CONSIDERAÇÕES FINAIS}

Ao considerar os objetivos desta pesquisa, foi possível verificar que as categorias da Enfermagem possuem maior aproximação com o contexto da lavanderia devido à sua proximidade com o cuidar. As mesmas conseguem explicitar o uso da roupa e a reconhecem como essencial para um cuidado de qualidade. Porém, de todas as categorias profissionais, emergem informações importantes visto que suas atitudes incorretas trazem prejuízo ao cuidado.

Também observou-se que os profissionais médicos apresentaram um distanciamento desse contexto, assim como os estudantes de graduação. Demonstram aproximação somente do uniforme utilizado, não compreendendo peças como lençol, camisolas, cobertores que são utilizados no cuidado. Desconhecem os diversos tipos de peças que a lavanderia processa para atender a todo tipo de procedimento realizado no hospital.

O entendimento sobre a roupa hospitalar na prática do cuidado não está muito claro para os profissionais de saúde e estudantes de graduação que trabalham com a roupa diariamente. Parece que ela é invisível.

Em relação ao processamento das roupas, o distanciamento foi mais relevante. A maioria dos profissionais e estudantes não conhece o trabalho da lavanderia e, por isso, não se considera parte integrante do processo, desconhecendo como suas atitudes podem interferir negativamente no processamento da roupa e na prática do cuidado.

Este estudo apresenta como proposta de intervenção realizar atividades de educação permanente com todos os profissionais que utilizam a roupa, na prática do cuidado, por meio de capacitações. Uma proposta de atuação na formação acadêmica é manter diálogo com as unidades educacionais sobre esse tema nos cursos de Medicina e Enfermagem da faculdade ligada ao hospital para que haja aproximação da teoria com a prática.

\section{REFERÊNCIAS}

1. Garcia IF, Rodrigues ICG, dos Santos VLP, Ribas JLC. Humanização na hotelaria hospitalar: um diferencial no cuidado com o paciente. Rev Saúde e Desenvolvimento. [Internet] 2016;10(5) [acesso em 25 out 2017]. Disponível: https://www.uninter.com/revistasaude/index.php/saudeDesenvolvimento/article/view/603

2. Ministério da Saúde (BR). Portaria n. 3.390, de 30 de dezembro de 2013. Institui a Política Nacional de Atenção Hospitalar (PNHOSP) no âmbito do Sistema Único de Saúde (SUS), estabelecendo-se as diretrizes para a organização do componente hospitalar da Rede de Atenção à Saúde (RAS). Diário Oficial da União, [Internet] 31 dez. 2013 [acesso em 30 jan 2017]. Disponível: http://bvsms.saude.gov.br/bvs/saudelegis/gm/2013/ prt3390_30_12_2013.html.

3. Dias MAA. Humanização do espaço hospitalar: uma responsabilidade compartilhada. Mundo saúde. [Internet] 2006;30(2) [acesso em 00 mês 0000]. Disponível: https://www.saocamilo-sp.br/pdf/mundo_saude/35/ humanizacao.pdf.

4. Bartolomeu TA. Identificação e avaliação dos principais fatores que determinam a qualidade de uma lavanderia hospitalar: um estudo de caso no setor de processamento de roupas do Hospital Universitário da UFSC [dissertação]. Florianópolis (SC): Universidade Federal de Santa Catarina; 1998.

5. Lisboa TC, de Oliveira SL. Lavanderia hospitalar: reflexões sobre fatores motivacionais [tese]. São Paulo (SP): Universidade Mackenzie; 1998.

6. Agência Nacional de Vigilância Sanitária (ANVISA). Processamento de roupas em serviços de saúde: prevenção e controle de riscos. Brasília: Agência Nacional de Vigilância Sanitária; 2009.

7. Ministério da Saúde (BR). Secretaria Nacional de Ações Básicas de Saúde. Divisão Nacional de Organização de Serviços de Saúde. Manual de lavanderia hospitalar. Brasília: Ministério da Saúde; 1986. 
8. Fernandes DMM, Fernandes SB, Ferraza CAC. Gestão para a segurança e a qualidade de vida no trabalho em uma lavanderia hospitalar, Brasil. Rev Adm Saúde. [Internet] 2013;15(61) [acesso em 02 nov 2015]. Disponível: http://www.cqh.org.br/portal/pag/anexos/baixar.php?p_ndoc=1021\&p_nanexo=\%20509

9. Ferreira KLP, Silva RM, Oliveira Júnior LB. Gerenciando enxoval hospitalar: redução dos custos nas unidades de serviço de saúde. In: Anais do $2^{\circ}$ Congresso Brasileiro de Política, Planejamento e Gestão em Saúde; 2013 Out. Belo Horizonte, Brasil. Rio de Janeiro: ABRASCO; 2013. P.23.

10. Farias RM, Picchiai D, Junior EAS. O controle higiênico-sanitário como indicador de desempenho e qualidade na lavanderia hospitalar. Rev Gest Sist Saúde. [Internet] 2016;5(1) [acesso em 25 out 2017]. Disponível: http:// dx.doi.org/10.5585/rgss.v5i1.178

11. Barbosa JG, Meira PL, Dyniewicz AM. Hotelaria hospitalar: novo conceito em hospedagem ao cliente. Cogitare Enferm. [Internet] 2013;18(3) [acesso em 26 ago 2016]. Disponível: http://dx.doi.org/10.5380/ce.v18i3.33576.

12. Ceccim RB. Educação permanente em saúde: desafio ambicioso e necessário. Interface (Botucatu). [Internet] 2004;9(16) [acesso em 14 mar 2017]. Disponível: http://dx.doi.org/10.1590/S1414-32832005000100013.

13. da Silva JLBV, de Oliveira ABC, de Oliveira AGM, de Oliveira KD, Oliveira FMC, Alves MRR. A prática da integralidade na gestão do cuidado: relato de experiência. Rev Enferm UFPE on line. [Internet] 2017;11(2) [acesso em 26 out 2017]. Disponível:-http://pesquisa.bvsalud.org/portal/resource/pt/bde-30537.

14. Gonze GG. A integralidade na formação dos profissionais da saúde: tecendo saberes e práticas [dissertação]. Juiz de Fora (MG): Universidade Federal de Juiz de Fora; 2009.

15. Pereira AP. Governança em higiene e limpeza hospitalar: implicações para o trabalho da enfermagem [dissertação]. Ribeirão Preto (SP): Universidade de São Paulo de Ribeirão Preto; 2012.

16. Thofehrn MB, Montesinos MJL, Arrieira IC, Ávila VC, Vasques TCS, Farias ID. Processo de trabalho dos enfermeiros de um hospital da Espanha: ênfase nas tecnologias de cuidado. Cogitare Enferm. [Internet] 2013;19(1) [acesso em 11 maio 2017]. Disponível: http://dx.doi.org/10.5380/ce.v19i1.35972.

17. Turato ER. Decidindo quais indivíduos estudar. $6^{\mathrm{a}}$ ed. Petrópolis, RJ: Vozes; 2013. Tratado da metodologia da pesquisa clínico-qualitativa: construção teórico-epistemológica, discussão comparada e aplicação nas áreas da saúde e humanas. p. 351-68.

18. Bardin L. Análise de conteúdo. São Paulo: Edições 70; 2012.

19. Ministério da Saúde (BR). Conselho Nacional de Saúde. Diretrizes e normas regulamentadoras de pesquisa envolvendo seres humanos. Resolução n. 466, de 12 de dezembro de 2012. Brasília; 2012.

20. Borstmann RS, Witczak MVC. Sujidade presente e invisibilidade resultante: produção do desgaste de trabalhadores em uma lavanderia hospitalar. In: Anais da 5 Jornada de Pesquisa em Psicologia; 2015 Nov. Santa Cruz do Sul, Brasil. Santa Cruz do Sul: UNISC; 2015. p.5.

21. Dias LG, dos Santos GRN, Borges JRL, Costa LMM, Souza IC, Passos XS, et al. Processamento de artigos têxteis em lavanderia hospitalar: um relato de experiência, GO. Nursing. [Internet] 2012;15(171) [acesso em 30 jun 2017 ]. Disponível: http://pesquisa.bvs.br/brasil/resource/pt/bde-25328.

22. Dias JAA, de Souza DM, Azevedo BDS, Andrade IS, Nery PYG. O banho de leito na óptica de estudantes de graduação em enfermagem. Rev Pesqui Cuid Fundam Online. [Internet] 2016;8(4) [acesso em 10 jan 2017]. Disponível: http://dx.doi.org/10.9789/2175-5361.2016.v8i4.5087-5094.

23. Mitchell A, Spencer M, Edmiston C. Role of healthcare apparel and other healthcare textiles in the transmission of pathogens: a review of literature. J. hosp. infect. [Internet] 2015;90(4) [acesso em 28 jun 2017]. Disponível: http://dx.doi.org/10.1016/j.jhin.2015.02.017.

24. Lisboa TC. Processamento da roupa hospitalar. In: Torres S, Lisboa TC. Gestão dos serviços: limpeza, higiene e lavanderia em estabelecimentos de saúde. São Paulo: Sarvier; 2014. p. 221-63.

25. Assis MMA, Nascimento MAA, Pereira MJB, Cerqueira EM. Cuidado integral em saúde: dilemas e desafios da enfermagem. Rev. bras. enferm. [Internet] 2015;68(2) [acesso em 15 maio 2017]. Disponível: http://dx.doi. org/10.1590/0034-7167.2015680221i. 
26. Bendassolli PF, Falcão JTR. Psicologia do trabalho sujo: revendo conceitos e pensando em possibilidades teóricas para a agenda da psicologia nos contextos de trabalho. Univ Psychol. [Internet] 2013;12(4) [acesso em 22 mar 2017]. Disponível: http://pesquisa.bvs.br/brasil/resource/pt/lil-712603. 